\title{
Colored aftereffects produced with moving edges
}

\author{
C. F. STROMEYER III ${ }^{1}$ AND R. J. W. MANSFIELD 2,3 \\ HAR VARD UNIVERSITY
}

Colored aftereffects that lasted as long as 6 weeks were produced with moving patterns of parallel black and white stripes or with black and white spirals. During adaptation, the patterns moved periodically in opposite directions, each direction paired with one illuminant, red or green. When the moving patterns were later viewed in white light, $S$ saw the red and green colors, but they were related in the opposite way to the direction of motion. The red and green aftereffects were also produced by other pairs of illuminants, red and white, white and green, reddish-yellow and white, and white and greenish-yellow. The aftereffects did not occur unless, during adaptation, the stripes moved in both directions, each direction paired with a different color. The aftereffect was elicited by stripe motion over the retina-it was seen when the eye swept over a pattern of stationary stripes. The aftereffect desaturated when the retinal orientation of the stripes was changed from the adaptation orientation. Saturation was increased by longer exposure and slower speed during adaptation and by faster speed and a more rapid rate of alternation during the test. The luminance of the adaptation light seemed to have little effect. The aftereffect did not transfer from one eye to the other, and it did not change retinal locus, as was shown when clear images of a colored square that lasted several days were produced with a spiral. $S$ fixated the spiral's center. The spiral rotated alternately in opposite directions. $A$ red square with a green surround was projected on the center of the spiral when it rotated in one direction; a green square with a red surround was used when it rotated in the other direction. Following $50 \mathrm{~min}$ of adaptation, colored images of the squares were seen when the center of the spiral was fixated and the direction of rotation sharply reversed.

Red and green aftereffects that lasted as long as 6 weeks were produced with patterns of black and white horizontal stripes that moved vertically or with rotating spirals. During adaptation, each

Fig. 1. The stimulus display; two moving black and white striped belts seen through windows in the black field. pattern alternated its direction periodically, one direction paired with a red illuminant and the other with a green illuminant. When the moving patterns were later viewed in white light, $S$ saw the red and green colors, but they were related in the opposite way to the direction of motion. The red and green aftereffects were produced not only with the pair of red and green illuminants but also with the pairs, red and white, green and white, reddish-yellow and white, and greenish-yellow and white.

The aftereffects show a relation between the direction of edge motion and color. The McCollough effect demonstrates a similar relation between the orientation of stationary edges and color (McCollough, 1965). McCollough alternately presented a vertical pattern of black and white stripes in orange light and a horizontal pattern in blue light. This produced a blue-green aftereffect on the vertical pattern and an orange aftereffect on the horizontal pattern. The color of the aftereffect depended on the orientation of the stripes on the retina, for tilting the head $90 \mathrm{deg}$ down to the side caused the colors to switch from one pattern to the other.

The present investigation is divided into three series of experiments. The first demonstrated that red and green aftereffects were produced when edges moved in opposite directions, each direction paired with a different color. The aftereffects did not occur when the edges moved in one direction at a constant speed, illuminated with various colors. The second series showed that the aftereffect did not transfer from one eye to the other, was highly dependent on the orientation and direction of motion of the edges relative to the retina, and could be precisely localized on the retina. The third series explored parameters of the adaptation situation that change the saturation and duration of the aftereffect.

The aftereffect was seen by 23 out of 26 males and by 29 out of 38 females.

\section{SERIES I}

I.1 The Paradigm Experiments

Red and green aftereffects were produced with moving striped belts and rotating spirals. During adaptation, the edges moved periodically in opposite directions, one direction paired with a green illuminant and the other paired with a red illuminant.

\section{I.1.a Experiment with Moving Belts ${ }^{4}$}

Apparatus. Figure 1 shows the stimulus display. The center spot is a lighted fixation point. Each black and white panel was constructed by placing strips of black tape (Scotch) on white chart paper (Leeds and Northrup), stretched in a continuous belt around two rollers. The black stripes were $0.5 \mathrm{in}$. wide (or $22 \mathrm{~min}$ visual angle), separated by 1 -in. white spaces ( $44 \mathrm{~min}$ ).

Each belt was illuminated by two projectors used in alternation. The 
projectors were fitted with $300-W$ bulbs. A green filter (Wratten 55, dominant wavelength in Illuminant $A, 524.1 \mathrm{~nm}$ ) was placed before one projector and a red filter (Wratten 26, 620.6 $\mathrm{nm}$ ) before the other. Without the filters, the luminance of the black stripes and white spaces was 76 and $91 \mathrm{~dB}$ re $10^{-10} \mathrm{~L}$. During the test, the display was illuminated by the fluorescent room lights and the projectors without filters. The white spaces were then $92 \mathrm{~dB}$.

A timer clicked every $10 \mathrm{sec}$ to signal an alternation of the direction of stripe motion and the green and red projectors.

Subjects. Ss were male and female Harvard students and staff.

Procedure. Seated $2 \mathrm{~m}$ from the display, $S$ looked at the fixation point for $20 \mathrm{~min}$. The two belts moved in opposite directions, each at a rate of 3.8 stripes/sec ( $4 \mathrm{deg} 9 \mathrm{~min} / \mathrm{sec}$ ). The direction of motion changed every $10 \mathrm{sec}$. Each belt moved in one direction in green light and in the opposite direction in red light. Two Ss adapted to green-up (g-u) and to red-down $(\mathrm{r}-\mathrm{d})$, and two adapted to the converse condition. Then followed a 5-min test period with both belts illuminated in white light. $S$ reported the apparent color of the belts as the belts continued to alternate every $10 \mathrm{sec}$.

Results. In the test, all Ss saw the red and green colors, but they were related in the opposite way to the direction of motion in comparison to the adaptation condition. That is to say, if $\mathrm{S}$ had adapted to $g-u$ and $r-d$, then the test belts appeared pink, rose, or red when they moved upward and green or blue-green when they moved downward. The colors were most saturated just after the belts changed direction and faded throughout the $10-\mathrm{sec}$ period. At the beginning of the test period, the belts appeared gray, and not until 30 to $70 \mathrm{sec}$ later did the red and green appear. Perhaps a gray afterimage, due to stimulation with both red and green during adaptation, obscured the initial color effect.

After the 5-min test period, the direction of movement was alternated every $2 \mathrm{sec}$, and $\mathbf{S}$ adjusted the speed of the stripes until the colors appeared most saturated. Rates for individual Ss were $4.7 \mathrm{stripes} / \mathrm{sec}$ ( $5 \mathrm{deg} 8 \mathrm{~min} / \mathrm{sec}$ ), $4.7,5.3$ (5 deg $47 \mathrm{~min}$ ), and 6.6 (7 deg $12 \mathrm{~min}$ ). The rates were higher than the adaptation rate, 3.8 stripes $/ \mathrm{sec}$. At about 2 stripes $/ \mathrm{sec}$ ( $2 \mathrm{deg} 11 \mathrm{~min} / \mathrm{sec}$ ), the colors vanished.

\section{I.1.b Experiment with Rotating Spiral}

Apparatus. A 5-turn, black-on-white arithmetic spiral, $19 \mathrm{~cm}$ in diam, was employed. The black spiral line was $4 \mathrm{~mm}$ wide (or $7 \mathrm{~min}$ ), and the white space separating adjacent lines was $15 \mathrm{~mm}$
(26 min). Projectors with $100-\mathrm{W}$ bulbs iluminated the spiral with green light (Wratten 55) on one side and red light (Wratten 26) on the other side. The light formed a sharp green-red boundary, dividing the spiral vertically through the center. The white area of the spiral, illuminated by the projectors without filters, was $85 \mathrm{~dB}$ re $10^{-10} \mathrm{~L}$. The same area illuminated by the fluorescent room lights was $86 \mathrm{~dB}$.

Procedure. $\mathrm{S}$ sat $2 \mathrm{~m}$ from the spiral and fixated the center for $10 \mathrm{~min}$ while the spiral rotated at $2.6 \mathrm{cps}$ alternately for 10-sec periods in the expanding and contracting directions. Each stripe moved at $1 \mathrm{deg} 26 \mathrm{~min} / \mathrm{sec}$. The spiral was illuminated with green light on one side and with red on the other when it rotated in one direction; the colors were reversed when it rotated in the opposite direction. After adaptation, the spiral was illuminated with white light, and $S$ reported the colors seen on both sides of the spiral as it continued to rotate in alternate directions. Additional tests were made the following day and, for some $S s, 5,6,18$, and 28 days later.

Results. Four of the five Ss saw the red and green aftereffects. The colors were related in the opposite way to the direction of motion in comparison to the adaptation condition. That is to say, adaptation to expanding, green-right and red-left, and contracting, red-right and green-left, produced the aftereffect, expanding, red-right and green-left, and contracting, green-right and red-left. There were individual differences. $\mathrm{DB}, \mathrm{KK}$, and $\mathrm{MS}$ saw the colors fade 2 to $3 \mathrm{sec}$ after the direction of the spiral changed. The colors lasted $6 \mathrm{sec}$ for EN. DB and MS saw the colors separated by a sharp vertical boundary cutting the spiral in half. $\mathrm{KK}$ and EN noted narrow sectors of white oriented vertically.

On the second day, all four Ss again saw the aftereffects. Some Ss reported that the colors faded more quickly when the direction of the spiral changed. All Ss said that they did not remember the conditions of the previous day.

Faint colors segregated by boundaries were still seen by DB when tested after 6 days, by KK after 5 and 18 days, and by MS after 28 days. After 5 days, EN saw green color in localized quadrants of the spiral. All Ss reported that the colors faded quickly each time the direction of the spiral was reversed.

The aftereffect appeared highly localized on the retina, for the vertical boundary of the aftereffect tilted as $\mathrm{S}$ tilted his head down to the side, and it was seen clearly only when the spiral's center was fixated.

\subsection{Other Adaptation Colors}

The red and green aftereffects were generated when the spiral was presented with the pairs of illuminants, red and white, white and green, reddish-yellow and white, and white and greenish-yellow.

\section{I.2.a Red and White; White and Green}

Procedure. Three Ss adapted to conditions similar to the spiral paradigm experiment. When the spiral turned in one direction; it was illuminated red-right and green-left by projectors with $300-\mathrm{W}$ bulbs; when it turned in the opposite direction, it was illuminated by white light by a projector with a $100-\mathrm{W}$ bulb. The white area of the spiral illuminated by the 300 . and $100-\mathrm{W}$ projectors without filters was 92 and $85 \mathrm{~dB}$ re $10^{-10} \mathrm{~L}$. The test was the same as before.

Results. All three Ss saw aftereffects similar to those of the paradigm experiment. For example, adaptation to expanding, red-right and green-left, and contracting, white, produced the aftereffects, expanding, green-right and red-left, and contracting, red-right and green-left. Every $S$ noted that the aftereffects were more saturated when the spiral rotated in the direction in which it had been white during adaptation. One $S$, $90 \mathrm{~min}$ after adaptation, and another $S, 4 \mathrm{~h}$ after adaptation, saw the aftereffects when the spiral rotated in the direction in which it had been white during adaptation, but no aftereffects when it rotated in the other direction-the direction in which it had been colored.

\section{I.2.b Reddish-Yellow and White; White and Greenish-Yellow}

Procedure. The procedure was similar to that of the paradigm experiment. Three Ss adapted for $30 \mathrm{~min}$ (six 5 -min periods, each separated by a 4-min rest period). When the spiral expanded, projectors with $1,000-W$ bulbs illuminated the left side with reddish-yellow light (Wratten 22, dominant wavelength in Huminant $A$, $598.8 \mathrm{~nm}$ ) and the right side with greenish-yellow light (Wratten 8K2, $581.2 \mathrm{~nm})$. When the spiral contracted, it was illuminated with white light by the 100-W projector. During the test, the $100-W$ projector and room lights were on.

Results. In the test, one $S$ observed that when the spiral started to contract, the left side appeared reddish and the right appeared yellowish-green. The colors lasted about $5 \mathrm{sec}$ each time the spiral started to contract. Both sides were white when the spiral expanded. The second $S$ reported about the same colors as the first $S$ for the contracting spiral-red, tending toward maroon, on the left and green, a shamrock green, on the right. The colors reversed 
sides when the spiral expanded. The colors lasted about $2.5 \mathrm{sec}$ for each direction, but the contracting spiral gave a more saturated aftereffect. The next day, the aftereffect was still clearly visible. The third $\mathrm{S}$ saw no colors.

Discussion. The red and green aftereffects were produced by colors that were predominantly yellow. It appears that the color of the aftereffect is determined by the redness and greenness of the adaptation color. A reddish-yellow, that was only slightly reddish, functioned as a red illuminant, whereas a greenish-yellow, that was only slightly greenish, functioned as a green illuminant. One of the authors tried adapting with blue filters and found the aftereffects too weak to determine whether or not their colors depended on the redness and greenness of adaptation colors in the blue region of the spectrum.

Pairs of illuminants, each comprising a chromatic color (in the green-yellow-red region) and white, produced red and green aftereffects. The next set of experiments demonstrated that the aftereffects were not obtained unless both the direction of edge motion and the color were concomitantly alternated during adaptation.

\section{I.3 Alternation of Color and Edge Motion}

The present experiments show that the aftereffects require an adaptation procedure in which different colors are paired with different types of edge motion.

In the first experiment, the red and green illuminants on either side of the spiral were not alternated. The spiral rotated in only one direction during adaptation but in both directions during the test. The test commenced 20 min after adaptation; this presumably gave time for the afterimages to fade. The procedure was otherwise identical to the paradigm experiment.

Four Ss saw no aftereffects, whereas the fifth $S$ saw weak complementary colors near the edge of the spiral line as the spiral rotated in the same direction as during adaptation. The experiment was then repeated using a 15 -min adaptation period and the $300-W$ projectors rather than the $100-W$ projectors. Again, neither of the two Ss saw any aftereffects.

A second variation was then tried: The green (right) and red (left) illuminants on either side were not alternated as before; however, the direction of rotation was changed every $10 \mathrm{sec}$. The $300-\mathrm{W}$ projectors were used.

Two Ss saw no aftereffects. A third S saw very faint red-right and green-left every time the spiral changed direction, but this effect completely vanished within a day. It thus appears that the aftereffect requires an alternation of the adaptation color.

The next experiment demonstrated that alternation of the colors was not sufficient: The direction of rotation must also alternate. Three Ss adapted for $10 \mathrm{~min}$ to alternating 10-sec exposures of white light and green-right, red-left. The $300-\mathrm{W}$ projectors were used. The spiral rotated in only one direction during adaptation but in both directions during the test. Once the afterimages had faded, no $S$ saw an aftereffect.

\section{Discussion}

The aftereffect appears to depend on a concomitant variation of the direction of edge motion and color during adaptation. However, Hepler ${ }^{5}$ found that aftereffects could also be produced with edges moving in only one direction by pairing different colors with different speeds. The mechanism of the aftereffect may produce a similar but weaker response to edges moving in one direction at different speeds than to edges moving in opposite directions. The mechanism may be especially sensitive to the relative motion of two sets of edges.

The aftereffects might neutralize color differences specific to the direction of edge motion. The advantage of this process in nonartificial situations is nowise obvious. It may help account for such phenomena as the colors related to eye position that are seen after prolonged wearing of split-field colored spectacles (Kohler, 1964). For example, with spectacles on during forward motion, different directions of edge motion may be systematically related to different colors. With the spectacles removed, eye movements may cause edges to sweep over the eye, evoking colored aftereffects. The aftereffects may simply reflect an economy of neural units: Some units might encode information about both edge motion and color.

\section{SERIES II}

This series of experiments demonstrates that the aftereffect does not transfer from one eye to the other, is highly dependent on the orientation and direction of edge motion relative to the retina, and may be precisely localized on the retina.

\section{II.1 No Interocular Transfer}

The procedure was the same as the paradigm experiment with the striped belts, except that $S$ fixated with only the right eye during adaptation and with each eye separately during the test. All four Ss reported the red and green aftereffect using the right eye and no aftereffect using the left eye. No transfer occurred.

The two eyes were then adapted to opposite conditions to see whether or not
$S$ would see opposite aftereffects 'as he shifted from one eye to the other. One eye was adapted to $g-u$ and $r-d$ and the other to $r-u$ and $g-d$. During the $30-m i n$ adaptation period, $\mathbf{S}$ shifted from one eye to the other at 1-min intervals. Two Ss saw, with each eye, the aftereffects appropriate for the stripe motion for that eye. The third $S$ saw pink with each eye when the belts moved in the direction in which they had been green during adaptation and white when they moved in the opposite direction.

The effect does not transfer interocularly, and the two eyes may be adapted simultaneously to conditions that produce opposite aftereffects. The McCollough effect (McCollough, 1965) and phantom fringes produced by wearing prisms were likewise restricted to the eye adapted (Hajos \& Ritter, 1965).

\section{II.2 Sensitivity to Retinal Orientation}

Procedure. Seven Ss adapted as in the paradigm experiment with the striped belts. The Ss who saw aftereffects were told to tilt their heads down toward the right and left to locate the point on each side at which the colors vanished. This was done for three trials. $S$ fixated the center point as he tilted his head; his chin, in a rest, formed a pivot. The direction of stripe motion was alternated every 2 sec.

Four other Ss also adapted as in the paradigm experiment. After adaptation, $S$ tilted his head down toward the right and left to locate the point on each side at which the colors appeared one-half as saturated as when the head was upright and also the point at which the colors vanished. This was done for four trials. The direction of stripe motion was again alternated every $2 \mathrm{sec}$.

Results. Table 1 shows, for individual Ss, the means and ranges of head tilt measured from a head-upright position, the left-right distinction being disregarded. The colors disappeared when the head was tilted $25 \mathrm{deg}$ (the arithmetic mean of all observations); at $15 \mathrm{deg}$, the colors appeared one-half as saturated as when the head was upright

Discussion. To elicit the aftereffect, the orientation of the stripes on the retina must be similar to the orientation during adaptation. When the head tilted, the colors rapidly desaturated. When $S$ completely inverted his head, the colors appeared again quite saturated, but their relationship to the movement of the stripes was reversed. The aftereffect thus depends on the direction of edge motion relative to the retina, not to the environment.

Another motion aftereffect showed less sensitivity to edge orientation. Sekuler (1967) measured the luminance threshold for seeing a set of moving black-and-white 
Table 1

Head Tilt (from an Upright Position) at Which the Panels Appear Black and White and at Which the Colors Appear One Half as Saturated as They Appeared with the Head Upright

\begin{tabular}{|c|c|c|c|c|}
\hline \multirow[b]{2}{*}{$\mathbf{S}$} & \multicolumn{2}{|c|}{$\begin{array}{c}\text { Panels Appear } \\
\text { Black and } \\
\text { White }\end{array}$} & \multicolumn{2}{|c|}{$\begin{array}{c}\text { Colors Appear } \\
\text { One Half } \\
\text { as Saturated }\end{array}$} \\
\hline & \multicolumn{2}{|c|}{ (Degrees) } & \multicolumn{2}{|c|}{ (Degrees) } \\
\hline 1 & 11 & $7-14$ & & \\
\hline 2 & 10 & 8.13 & & \\
\hline 3 & 34 & $26-40$ & & \\
\hline 4 & 26 & $22-31$ & & \\
\hline 5 & 24 & $35-45$ & & \\
\hline 6 & 35 & $28-45$ & & \\
\hline 7 & 37 & $35-41$ & 22 & $18-27$ \\
\hline 8 & 22 & $16-33$ & 10 & $8-12$ \\
\hline 9 & 36 & $23-44$ & 19 & $14-27$ \\
\hline 10 & 18 & $13-26$ & 9 & $6-13$ \\
\hline Means & 25 & $21-33$ & 15 & $12-20$ \\
\hline
\end{tabular}

bars after adapting to the same set of moving bars. The orientation between the adaptation and test bars was varied. The threshold was highest when both sets had the same orientation and direction of motion. The threshold decreased as the orientation difference increased. At 45 deg, the threshold increase due to adaptation was half the maximal value. Even at $50 \mathrm{deg}$ and $60 \mathrm{deg}$, the threshold was considerably elevated.

Two other studies have shown that the movement aftereffect does not affect orthogonal edges. Pantle and Sekuler ${ }^{6}$ found that adaptation to a set of horizontal bars moving vertically raised the luminance threshold for seeing a stationary set of horizontal bars but did not affect a vertical set. Wohlgemuth (1911) observed a great decrease in the duration of the waterfall illusion produced by vertical bars moving alternately leftward and rightward. The decrease had no effect on the duration of the illusion produced by horizontal bars moving upward and downward.

Orthogonal directions of edge motion thus appear independent in regard to the movement aftereffect. Opposite directions, however, do not appear independent. Wohlgemuth (1911) found that alternating the direction of edge motion considerably reduced the duration of the waterfall illusion, compared to not alternating the direction. Roehrig and Rutschmann (1963) found the same result with the spiral aftereffect.

The colored aftereffects produced with moving edges may show a similar relation of dependence between opposite directions of motions and of independence between orthogonal directions. For example, no aftereffects may result from adapting to edges moving in one vertical direction and one horizontal direction. (It has already been shown that the aftereffect requires adaptation with color varying concomitantly with direction of edge motion.) In contrast, two independent sets of aftereffects may result from adapting to edges moving in both vertical directions and in both horizontal directions.

\section{II.3 Aftereffect Elicited with Stationary Edges}

In the test, the eyes swept over a pattern of stationary stripes. The color of the aftereffect depended on the direction of stripe motion over the retina.

Apparatus. For the test, a sheet of white paper, bearing the stripes similar to the moveable belts, was placed over the entire right side of the display. The left edge of the sheet coincided with the right edge of the left belt

Procedure. Adaptation was the same as in the paradigm experiment. All four Ss had seen the aftereffect in previous experiments. During the test, $S$ kept his eye on a particular stripe on the left belt, which moved at 4.8 stripes $/ \mathrm{sec}$. E alternated the stripe's direction each time it reached the top and bottom of the display window. This helped the eyes move smoothly over the stripes on the stationary sheet.

Results. All Ss reported seeing distinctly the aftereffect on the stationary sheet. The colors depended on the direction in which the stripes moved over the eye. (Consider, for example, an $S$ who fixated the stationary sheet and saw the left belt moving upward as green and downward as red. When the eye, instead, followed the left belt moving upward, the right side appeared red not green, for the stationary pattern swept downward over the eye.)

Discussion. The aftereffect depends on the direction of edge motion over the retina. $S$ need not actually see the stripes move to experience the aftereffect. Thus, a stationary $S$ in a moving world may give rise to the same aftereffects as a moving $S$ in a stationary world. If the aftereffect was made very strong, $S$ might see colors in many situations where eye movements make edges sweep over the eye.

Antis and Gregory (1965) showed that the waterfall illusion likewise depended on the direction of edge motion relative to the eye. Objective motion was not required. The illusion could be produced by sweeping the eyes over a pattern of stationary stripes during adaptation but could not be produced by having the eyes follow a pattern of moving stripes.

\section{II.4 Precise Retinal Locus: Aftereffect of Square Image}

\section{II.4.a Basic Experiment}

In the paradigm spiral experiment, the aftereffects often appeared segregated by a sharp red-green boundary that divided the spiral vertically through the center. Precise retinal localization of the aftereffect was more strikingly demonstrated in the present experiment. Colored adaptation lights that formed a square image on the spiral gave rise to persistent, clear square aftereffects.

Apparatus. The spiral was set against a black ground and surrounded by a black, square frame. Each side of the frame contained a black-tipped white rod that could be moved in toward the spiral's center to indicate the border of the square aftereffect.

During adaptation, the spiral was illuminated by projectors with 300 - or 100-W bulbs, which illuminated the white area of the spiral at 95 and $90 \mathrm{~dB}$ re $10^{-10} \mathrm{~L}$. To provide patterned light, two filters were made from the Wratten fitters, 26 and 55, a green square with red surround and a red square with green surround. The $300-\mathrm{W}$ projectors were used to project a square image of light, $54 \times 54 \mathrm{~mm}$, not quite concentric with the spiral. The two squares coincided.

Procedure. S sat $150 \mathrm{~cm}$ from the spiral, with his chin in a rest, and fixated the spiral's center for successive 5-min periods, separated by $15-$ to $30-$ min rest periods. Four Ss adapted for 10 periods. A fifth $\mathrm{S}$ adapted for 8 periods the 1 st day and 8 the 2nd, and a sixth $\mathbf{S}$, for 3 the 1 st day and 7 the 2 nd. The spiral rotated at $2.9 \mathrm{cps}$ ( $2 \mathrm{deg}$ $5 \mathrm{~min} / \mathrm{sec}$ ) in the expanding and contracting direction, alternating every $10 \mathrm{sec}$. Four Ss adapted to expanding, green square with red surround, and contracting, red square with green surround. Two Ss adapted to the converse condition.

Immediately following the last adaptation period, $S$ reported what he saw while fixating the spiral's center. The spiral rotated as before, illuminated only by the fluorescent room lights. If $S$ saw an image similar to the adaptation patterns, he instructed $E$ to move the rods until their tips coincided with the borders of the subjective image. $S$ also made judgments at distances further removed from the spiral. A chin rest was always used. The effects of speed of rotation and rate of alternation of the spiral's direction were also investigated. Some Ss were tested again on the 2nd and 3rd days.

Results. Five Ss saw sharp square aftereffects. The colors of the square and its surround were similar to the adaptation patterns, but they were related in the opposite way to the direction of motion. (For example, adaptation to expanding, green square with red surround, and contracting, red square with green surround, produced the aftereffect, expanding, red square with green surround, 
Table 2

Difference in $\mathrm{mm}$ Between Projector Image and Subjective Image Viewed on Center of Spiral at a Distance of $150 \mathrm{~cm}$ (Positive and Negative Numbers Indicate that the Subjective Image is Greater than or Less than the Projector Image

\begin{tabular}{|c|c|c|c|c|c|}
\hline $\mathbf{S}$ & Day & $\begin{array}{l}\text { Top } \\
\text { Side }\end{array}$ & $\begin{array}{c}\text { Bottom } \\
\text { Side }\end{array}$ & $\begin{array}{l}\text { Left } \\
\text { Side }\end{array}$ & $\begin{array}{r}\text { Right } \\
\text { Side } \\
\end{array}$ \\
\hline $\mathrm{CC}$ & $\begin{array}{l}1 \\
2 \\
3\end{array}$ & $\begin{array}{r}-1 \\
4 \\
3\end{array}$ & $\begin{array}{r}1 \\
1 \\
-2\end{array}$ & $\begin{array}{r}-1 \\
4 \\
3\end{array}$ & $\begin{array}{l}-4 \\
-5 \\
-8\end{array}$ \\
\hline DH & $\begin{array}{l}1 \\
2\end{array}$ & $\begin{array}{r}18 \\
8\end{array}$ & $\begin{array}{l}7 \\
7\end{array}$ & $\begin{array}{l}3 \\
0\end{array}$ & $\begin{array}{l}0 \\
2\end{array}$ \\
\hline $\mathrm{CS}$ & $\begin{array}{l}1 \\
2 \\
3\end{array}$ & $\begin{array}{r}0 \\
2 \\
-2\end{array}$ & $\begin{array}{l}2 \\
2 \\
1\end{array}$ & $\begin{array}{r}1 \\
-1 \\
6\end{array}$ & $\begin{array}{r}2 \\
-1 \\
-2\end{array}$ \\
\hline BB & $\begin{array}{l}1 \\
2 \\
3\end{array}$ & $\begin{array}{r}13 \\
3 \\
7\end{array}$ & $\begin{array}{r}-1 \\
0 \\
2\end{array}$ & $\begin{array}{r}0 \\
-2 \\
-2\end{array}$ & $\begin{array}{l}4 \\
2 \\
3\end{array}$ \\
\hline $\mathbf{S M}$ & $\begin{array}{l}1 \\
2 \\
\end{array}$ & $\begin{array}{l}3 \\
4 \\
\end{array}$ & $\begin{array}{l}5 \\
6 \\
\end{array}$ & $\begin{array}{l}4 \\
5\end{array}$ & $\begin{array}{l}0 \\
3 \\
\end{array}$ \\
\hline SM & $\begin{array}{l}1 \\
2\end{array}$ & $\begin{array}{l}2 \\
4\end{array}$ & $\begin{array}{l}6 \\
2\end{array}$ & $\begin{array}{l}3 \\
2\end{array}$ & $\begin{array}{l}-3 \\
-2\end{array}$ \\
\hline BB & $\begin{array}{l}1 \\
2\end{array}$ & $\begin{array}{l}10 \\
10\end{array}$ & $\begin{array}{l}4 \\
1\end{array}$ & $\begin{array}{l}4 \\
1\end{array}$ & $\begin{array}{l}3 \\
2\end{array}$ \\
\hline
\end{tabular}

and contracting, green square with red surround.) The sixth $S$ did not see the square but did see pink at the spiral's center when the direction changed from contracting to expanding; he had adapted to expanding, green square.

The coincidence between the subjective image and adaptation patterns was indicated by the rod settings. $S$ was generally satisfied with his judgment after viewing the spiral alternate 10 to 15 times. Table 2 shows the extent of coincidence for each side of the square. Note that the coincidence is greater for the left and right sides than for the top and bottom sides. Some Ss reported that the top and bottom sides were often difficult to judge, and that they might have removed their eyes from the spiral's center.

Figure 2 shows the size of the subjective image as a function of viewing distance from the spiral. The solid line shows the area of the adaptation pattern as the projector is moved along a line normal to the spiral's center. The area changes proportionally with the square of the distance between projector and spiral. The data of CC fall near the line. The data of the other Ss are nearly parallel with the line. The top and bottom sides were set, on the average, $14.4 \%$ larger than the adaptation pattern, whereas the left and right rods were set only $2.4 \%$ too large. As remarked earlier, Ss had difficulty judging the top and bottom sides. It appears that the image follows Emmert's law of afterimages:

The effects of rotation speed and alternation rate were examined at $150 \mathrm{~cm}$. The best formed squares were seen by individuals at the speeds: $2.9,2.9,2.9$, 2.9-3.2, and $3.2 \mathrm{cps}$. The squares became indistinct at slower (2.6 cps) and faster (3.4 cps) rates. A rate of $2.9 \mathrm{cps}$ had been used for adaptation. Four Ss reported that when the direction of rotation was alternated every $2 \mathrm{sec}$, the square was not seen but, rather, color was seen radiating from the center. At the 10- and 20-sec rates, all Ss clearly saw the square; two Ss saw the square more distinctly at the $20-\mathrm{sec}$ rate. The sharpness of the square thus appears to increase to an asymptote as the rate of alternation decreases.

\section{II.4.b A Variation of the Experiment}

The experiment was essentially repeated with the filter removed from one of the two adaptation projectors.

Procedure. Two of the Ss from the previous experiment adapted for five 10-min periods, separated by 1 -h rests. When the spiral rotated one way, it was illuminated by white light from the 100-W projector; when it rotated in the opposite direction, it was illuminated by the colored square, as before.

Results. The aftereffects were quite similar to those of the previous experiment. SM, who adapted to expanding, green square with red surround,

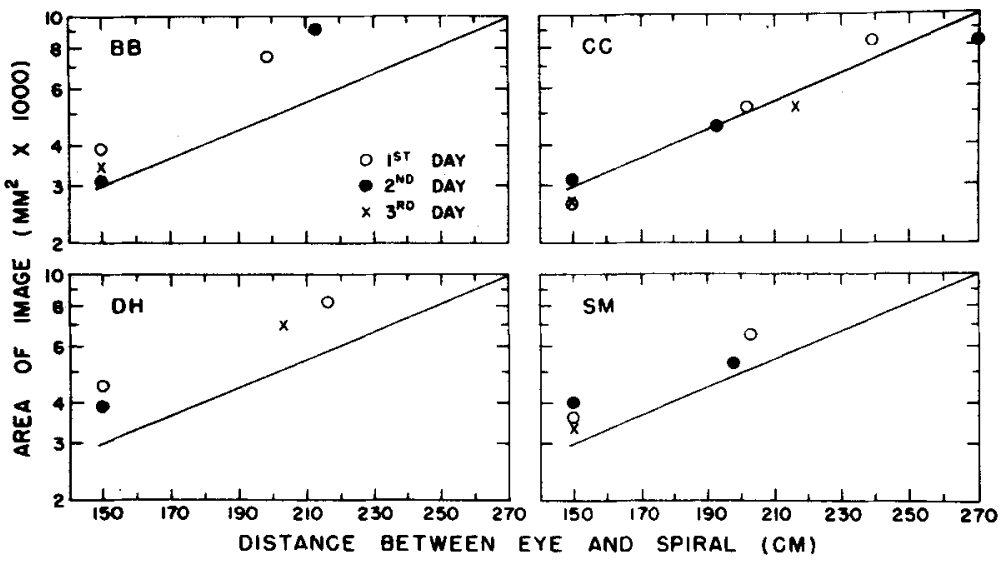

and contracting, white, saw the aftereffect, expanding, a "squarish" patch of faint red with green surround, and contracting, a clearly defined green square with red surround. BB, who adapted to expanding, white, and contracting, red square with green surround, saw the aftereffect, expanding, a "really well formed" red square with green surround, and contracting, a "hazy" green square with pink surround. Thus, distinct squares, in the hues of the adaptation patterns, were seen only when the spiral rotated in the direction in which it had been white during adaptation.

The 2nd day, SM saw expanding, nothing, and contracting, green square with red surround; the square was as sharp as on the 1 st day but less saturated. The 3rd day, the square was still fainter. The 2 nd day, BB saw expanding, red square with green surround, weaker than on the 1st day, and contracting, a green patch with white surround. The colors were still weaker the 3rd day.

The bottom of Table 2 shows the coincidence of the subjective image and adaptation pattern, viewed at a distance of $150 \mathrm{~cm}$ on the 1 st and $2 \mathrm{nd}$ days.

Discussion. The subjective square was seen only at the point when the direction of rotation was reversed. The image then flashed very briefly in luminous colors. A moment later, the color in the square turned into a pattern of color that radiated out from the center of the spiral beyond the square's border. This fact conflicts with an interpretation of the aftereffect in terms of highly localized adapted elements.

In the first experiment, the square appeared most distinct when the test speed nearly matched the adaptation speed. This coincidence might be quite accidental.

This series of experiments has shown that the aftereffect is restricted to the eye adapted, may be highly localized on the retina, and is dependent on the orientation and direction of edge motion over the eye in relation to the adaptation conditions.

\section{SERIES III}

Various adaptation parameters were examined to see what controlled the saturation of the aftereffect. The aftereffect appeared stronger when the stripes moved in a direction in which they

Fig. 2. Area of the subjective squares that each of the four Ss saw while fixating the center of the spiral from various viewing distances on the 1st, $2 \mathrm{nd}$, and $3 \mathrm{rd}$ days. The solid line represents the area of the adaptation pattern as the projector is moved along a line normal to the spiral's center. 
had moved either proportionally slower or proportionally longer during adaptation. A longer adaptation period also produced a stronger aftereffect. In contrast, the intensity of the adaptation illuminant did not appear to affect the aftereffect.

\section{III.1 Duration}

Procedure. Same as the paradigm experiment, except that one belt was exposed for $20 \mathrm{~min}$ and the other for the last $5 \mathrm{~min}$ of the $20-\mathrm{min}$ period.

Results. Three Ss saw a more saturated aftereffect on the belt that had been exposed for $20 \mathrm{~min}$; the fourth $S$ saw no difference between the two belts. The saturation difference was still seen by two Ss 1 day after adaptation and by a third $S$ 2 days after adaptation. Three other Ss saw no aftereffects.

\section{III.2 Different Durations for Different Directions}

Procedure. Same as the paradigm experiment, except that the belts moved alternately in one direction for $20 \mathrm{sec}$ and in the opposite direction for $10 \mathrm{sec}$. Each belt thus moved twice as long in one direction in one color than in the other direction in the other color. During the test, the direction was alternated every $10 \mathrm{sec}$

Results. Three of the six Ss saw a more saturated aftereffect when the belts moved in the direction in which they had been exposed longer during adaptation. The difference was still seen on the 2 nd day. Of the remaining Ss, one saw no aftereffect, a second saw no difference in saturation, and a third saw only the green aftereffect when one belt was moved upward, which was related to the longer exposure of red light.

\section{III.3 Speed}

Procedure. Same as the paradigm experiment, except that each belt moved in its opposite direction with a $3: 1$ speed ratio. For example, the left belt moved upward and the right downward at 1.6 stripes $/ \mathrm{sec}$ ( $1 \mathrm{deg} 45 \mathrm{~min} / \mathrm{sec}$ ); then the belts moved for $10 \mathrm{sec}$ in the reversed directions at 4.8 stripes $/ \mathrm{sec}$ ( $5 \mathrm{deg}$ $15 \mathrm{~min} / \mathrm{sec}$ )-like a seesaw moving slowly one way and rapidly the other. The test speed was the same as in the paradigm experiment, 3.8 stripes/sec.

Results. Three of the seven Ss saw the aftereffects definitely more saturated when the belts moved in the direction in which they had moved more slowly during adaptation. Two of these Ss, tested on the 2nd day, no longer saw the saturation difference. A fourth $S$ saw the red aftereffect equally saturated on both belts but the green aftereffect more saturated corresponding to the slower adaptation speed. The other three Ss, all females, saw no aftereffects.

Discussion. Pantle and Sekuler (1968) have demonstrated velocity-sensitive elements by adapting the eye to a pattern of black and white stripes moving with a given velocity and then measuring the luminance threshold for seeing the stripes when they move with various velocities. Thresholds were highest when the stripes moved at about the same speed and in the same direction as during adaptation. The authors suggest that different elements are maximally sensitive to different velocities.

The present experiment also demonstrates a speed sensitivity, as exemplified by the aftereffects. The aftereffects were stronger when the stripes moved in the direction in which they had moved more slowly during adaptation. This result may be due to the fact that a slow stripe motion alternated with a fast motion during adaptation. Hepler ${ }^{5}$ also demonstrated a speed sensitivity-different aftereffects were produced by edges moving in the same direction at different speeds, paired with different colors. Speed sensitivity should be tested without the interactions due to the use of several speeds within a single adaptation period. An experiment is suggested: An adaptation pattern moves in opposite directions at the same speed. The speed is varied each session. After each adaptation period, the saturation of the aftereffect is measured at various speeds of the test pattern.

\section{4 Illuminance}

The procedure was the same as in the paradigm experiment, but the white spaces of one belt were illuminated at $85 \mathrm{~dB}$ re $10^{-10} \mathrm{~L}$ by projectors with $100-\mathrm{W}$ bulbs. The other belt was illuminated at $91 \mathrm{~dB}$, as before, by projectors with $300-\mathrm{W}$ bulbs. Two of the four Ss saw the aftereffects equally saturated on both belts. The third $S$ saw only a faint aftereffect on the belt with the higher adaptation illuminance. The fourth $S$ reported green for one direction of one belt and faint red for the other direction of the other belt.

The experiment was then repeated with a greater illuminance difference between the two belts. One belt was illuminated by the $300 . \mathrm{W}$ projectors and the other by the $100-\mathrm{W}$ projectors, operating at reduced voltage so that the white spaces were $71 \mathrm{~dB}$. One $S$ saw a faint aftereffect equally saturated on both belts; on the 2nd day, only green was seen on one belt and red on the other. A second $S$ saw only the green aftereffect, which was more saturated on the belt with the higher adaptation illuminance. A third $\mathbf{S}$ saw off-white and pink, rather than red and green; the colors were slightly more saturated on the belt with the higher adaptation illuminance. On the 2 nd day, only a faint green was noted, equally saturated on both belts. The fourth $S$, after $4.5 \mathrm{~min}$ of testing, saw the green aftereffect on the belt with the higher adaptation illuminance. The same aftereffect was still seen the next day.

These results suggest that the adaptation illuminance may be reduced by 100 times $(20 \mathrm{~dB})$ without producing a marked change in the aftereffect. Even at low illuminances, the adaptation colors looked deeply saturated, although not very bright. The saturation of the aftereffect may depend on the color of the adaptation illuminant, especially the quantity of redness and greenness, and not on the luminosity.

\section{CONCLUSIONS ON PARAMETERS}

A longer exposure produced a more saturated aftereffect. A stronger aftereffect was also seen when the stripes moved in the direction in which they had been exposed proportionally longer. These conditions produced differences in saturation that were still seen on the 2 nd day. When the stripes moved in the direction in which they had moved proportionally slower during adaptation, a stronger aftereffect was again seen, but this difference did not seem to persist until the 2nd day. The luminance of the adaptation light, within wide limits, had only a minor effect. In the test period of the first paradigm experiment, an increase in the rate of stripe motion and the rate of alternation elicited a stronger aftereffect.

\section{PERSISTENCE OF THE AFTEREFFECTS}

Particular Ss were tested at various intervals after adaptation. The direction of stripe motion was alternated every $2 \mathrm{sec}$, and the speed was varied.

$A$ S in the paradigm and interocular experiments adapted to g-u and $\mathrm{r}-\mathrm{d}$. Five weeks later, he reported weak but "obvious" $r-u$ and $g-d$ on the right belt, lasting about $1 \mathrm{sec}$, each time the direction of stripe motion was alternated.

A $S$ adapted to $r-u$ and $g-d$ in the orientation experiment. Six weeks later, he still saw pink-down.

$A S$ in the speed experiment adapted to $r-u$ and $g-d$. One week later, she saw $g-u$ and $\mathrm{r}-\mathrm{d}$.

In the paradigm spiral experiment, the four Ss tested $5,6,18$, and 28 days after the 10-min adaptation period saw the aftereffects; in some cases, the colors were segregated by a vertical boundary.

With the passage of time, the duration of the aftereffect is shortened, so color is seen briefly when the direction of stripe motion 
is alternated. The color often appears as a faint flash. Ss often stated that they could not at all remember the adaptation conditions or their original reports.

\section{REFERENCES}

ANTIS, S. M., \& GREGORY, R. L. The after-effect of seen motion: The role of retinal stimulation and of eye movements. Quarterly Journal of Experimental Psychology, 1965 , 17, 173-174.

HAJOS, A., \& RITTER, M. Experiments to the problem of interocular transfer. Acta Psychologica, 1965, 24, 81-90.

KOHLER, I. The formation and transformation of the perceptual world. Psychological issues. Monograph 12. (Translated by H. Fiss.) New York: International Universities Press, 1964.

McCOLLOUGH, C. Color adaptation of edge-detectors in the human visual system. Science, 1965, 149, 1115-1116.
PANTLE, A. J., \& SEKULER, R. W. Velocity-sensitive elements in human vision: Initial psychophysical evidence. Vision Research, 1968, 8, 445-500.

ROEHRIG, W. C., \& RUTSCHMANN, J. Procedural considerations of the spiral aftereffect test. Perceptual \& Motor Skills, $1963,17,551-557$.

SEKULER, R. W. Movement analyzers in human vision. Paper presented in the symposium on Sensory mechanisms in visual perception, at the meeting of the American Psychological Association, September 1967.

WOHLGEMUTH, A. On the after-effect of seen movement. British Joumal of Psychology Monograph Supplement, 1911, 1, 1-117.

\section{NOTES}

1. Stromeyer held, during the term of the work, a NIH predoctoral fellowship and a National Research Council-AFOSR postdoctoral fellowship.
2. Address: Department of Psychology, Harvard University, Cambridge, Massachusetts 02138.

3. Mansfield held a National Research Council (Canada) Scholarship and wishes to express his appreciation for this support.

4. F or a similar experiment, see Hepler, $N$ Color: A motion-contingent aftereffect, Science, $1968,162,376-377$. She reported that the color aftereffects observed immediately after adaptation required a mean adaptation time of $135 \mathrm{~min}$, whereas the delayed aftereffects observed 20 to $27 \mathrm{~h}$ after adaptation, required $270 \mathrm{~min}$.

5. Hepler, N. Personal communication, 1969.

6. Pantle, A., \& Sekuler, R. W. Visual thresholds for moving and stationary gratings after inspection of moving gratings of variable contrast. Unpublished manuscript, 1968.

(Accepted for publication May 19, 1969.)

ERRATUM

PEARCE, D. G., \& MATIN, L. Variation of the magnitude of the horizontalvertical illusion with retinal eccentricity. Perception \& Psychophysics, 1969, 6 (4), 241-243.-Page 241, 2nd column, 2nd sentence of the 3id paragraph of the Procedure section should read as follows: "These positions were on the locus of a 100 in. sphere centered on S's left eye and located either on a longitude line 5 deg to the left of the primary vertical plane or on a latitude line 5 deg above the primary horizontal plane. The three test lights were always on the surface of this sphere." 